\title{
Health-related quality of life using specific and generic questionnaires in Spanish coeliac children
}

\author{
Josefa Barrio ${ }^{*^{*}}$, Maria Luz Cilleruelo², Enriqueta Román² and Cristina Fernández ${ }^{3}$
}

\begin{abstract}
Background: We aimed to compare the perception of health-related quality of life (HRQOL) and related factors in Spanish coeliac children and their parents, using two questionnaires, the generic KIDSCREEN-52 and the specific the Celiac Disease DUX (CDDUX), and to assess the correlation between them.

Methods: Coeliac children, aged 8-18, who are members of the Madrid Coeliac Association (MCA) and their parents, answered the Spanish version of the CDDUX and KIDSCREEN-52 questionnaires via e-mail. CDDUX was answered by 266 children and 428 parents and KIDSCREEN-52 by 255 children and 387 parents. Linear regression models were fitted to evaluate the association of demographic and clinical factors with HRQOL scores. CDDUX scores were compared with the subjective perception of health status assessed by the first question of KIDSCREEN52. The correlation between the questionnaires was analysed.
\end{abstract}

Results: We found that the main factors that negatively affected HRQOL were having social or economic difficulties associated with following the diet and having transgression-related symptoms. The maximum correlation between the questionnaires was 0.309 and -0.254 in parents and children respectively.

Conclusions: Although there is a poor correlation between the two questionnaires, both agreed that the main concerns of the respondents were related to the social and economic difficulties of following the diet. It would be interesting to use both types of questionnaires in order to perform a more complete assessment of HRQOL in coeliac children.

Trial registration: Not applicable.

Keywords: Coeliac disease, Quality of life, Questionnaires, Correlation, Health outcomes

\section{Introduction}

Coeliac disease $(\mathrm{CD})$ is an immune-mediated, systemic disorder due to gluten ingestion in genetically susceptible individuals [1]. Gluten-free diet (GFD) is currently the only effective treatment for $\mathrm{CD}$. Although adherence to the GFD resolves intestinal lesion and related symptoms, the obligation to follow a strict, restrictive and

\footnotetext{
*Correspondence: jbarrio.hflr@gmail.com

'Department of Paediatrics, Hospital Universitario de Fuenlabrada, Madrid, Spain

Full list of author information is available at the end of the article
}

permanent diet, together with the chronic nature of this illness, can have a considerable negative impact on coeliac patients and their families' health-related quality of life (HRQOL) [2,3] For these reasons, it is interesting to evaluate HRQOL in CD children and their parents and how the disease impacts on their lives. Over the last few years, the growing interest in evaluating HRQOL in $\mathrm{CD}$ children has led to the publication of many studies [4-7]. However, in Spain, it has not been studied sufficiently. For this reason, it was necessary to study it.

(c) The Author(s). 2020 Open Access This article is licensed under a Creative Commons Attribution 4.0 International License, which permits use, sharing, adaptation, distribution and reproduction in any medium or format, as long as you give appropriate credit to the original author(s) and the source, provide a link to the Creative Commons licence, and indicate if changes were made. The images or other third party material in this article are included in the article's Creative Commons licence, unless indicated otherwise in a credit line to the material. If material is not included in the article's Creative Commons licence and your intended use is not permitted by statutory regulation or exceeds the permitted use, you will need to obtain permission directly from the copyright holder. To view a copy of this licence, visit http://creativecommons.org/licenses/by/4.0/. The Creative Commons Public Domain Dedication waiver (http://creativecommons.org/publicdomain/zero/1.0/) applies to the data made available in this article, unless otherwise stated in a credit line to the data. 
The best way to evaluate HRQOL is using questionnaires. There are two main types, the generic and specific questionnaires. Generic questionnaires measure the daily life aspects of HRQOL in patients who have several conditions, whereas specific questionnaires focus on specific aspects related to the illness and its treatment [8].

The two questionnaires chosen to perform our study were the KIDSCREEN-52 and the CDDUX. The KIDS CREEN-52 questionnaire was chosen because it is one of the most widely used generic questionnaires worldwide [9] and has been translated into Spanish [10]. The Coeliac Disease DUX (CDDUX) [11] was chosen because it is the first paediatric disease-specific HRQOL questionnaire, it was recently adapted into Spanish by our group [12] and is also available in other languages [13-15].

Most HRQOL studies performed with coeliac children using either specific [13, 14, 16] or generic questionnaires [16-18] have observed no substantial negative impact on parents' and children's HRQOL, which is similar to our findings using the CDDUX [12] and the KIDS CREEN-52 [19]. However, some authors have found some negative impact $[11,15]$. Not many studies have evaluated coeliac children's HRQOL using a generic and a specific questionnaire. It is interesting to use both types of questionnaires because the information obtained with them is different, it can be complementary and useful for better assessing HRQOL.

The purpose of this study was to compare HRQOL outcomes and related factors (demographics: age, gender, parent educational level, living conditions as well as clinical factors: age upon diagnosis, time since diagnosis, clinical presentation at onset, family history of CD, associated diseases and disease follow-up data such as adherence to treatment, difficulties in following the diet and whether symptoms reappeared when gluten was ingested) in a group of coeliac children and their parents by using both the generic KIDSCREEN-52 and the specific CDDUX questionnaires, which focus on different aspects of the disease. A second objective was to assess whether there is a correlation between the results obtained with both questionnaires.

\section{Materials and methods}

\section{Ethics}

The study protocol was approved by the Clinical Research Ethics Committee of the Hospital Universitario de Fuenlabrada, Madrid, Spain. Informed consent was obtained from all parents or guardians and from all patients aged 12 years or older.

\section{Study participants}

This is a cross-sectional survey targeted at children from Madrid with CD aged 8 to 18 and their parents [12, 19]. In order to get a good representation of patients from around the Autonomous Region of Madrid, we contacted the Madrid Coeliac Association (MCA). Potential candidates were identified among their members in the target age range. Information about the study was sent via e-mail so as to reach the largest number of patients. Information about the study was sent to 1602 coeliac children, aged 8 to 18 , with an e-mail address associated with the MCA at that moment. Children and parents were instructed to independently access a link from the MCA webpage containing instructions and information about the study. The information sent included an informed consent form, the Spanish versions of the two questionnaires, demographic and clinical data. The CDDUX was the first questionnaire which people had access to, in order to prioritize answering the specific questionnaire, and, subsequently, they could access the KIDSCREEN-52 questionnaire.

The sample size was calculated according to the variance shown by the items in the questionnaire validation study [11]. The sample size required for 3\% accuracy and a $95 \%$ level of confidence $(95 \%$ CI) was 222 children and their parents. The recruitment process was halted upon acquiring the necessary number of participants.

As previously published elsewhere [12, 19], our sample was representative of the MCA population in terms of age and gender.

Demographic data recorded were: age, gender, parent educational level and living conditions. Clinical data collected were: age upon diagnosis, time since diagnosis, clinical presentation at onset, family history of $\mathrm{CD}$, associated diseases and disease follow-up data such as adherence to treatment, difficulties in following the diet and whether symptoms reappeared when gluten was ingested.

Participants were stratified by age upon questionnaire completion in: children (8-11 years old), young adolescents (12-15 years old) or older adolescents (16-18 years old), by age upon CD diagnosis $(<2-7$ and $>7$ years old), and by years since diagnosis $(<4$, 4-8 and $>8$ years old).

Factors related to QOL (demographic and clinical data) were analysed according to the total number of answers provided by the 428 patients whose parents answered the CDDUX questionnaire and by 387 patients whose parents answered to the KIDSCREEN-52 questionnaire (41 parents only answered the CDDUX questionnaire).

For the comparisons between both questionnaires, only the 387 and 255 parents and children's matched CDDUX and KIDSCREEN-52 questionnaires were taken into account.

The findings obtained in the univariate analysis using both questionnaires have been reported elsewhere [12, 19]. This present study provides results obtained in the 
multivariate analysis, as well as the comparison and correlation between the questionnaires.

\section{Questionnaire descriptions}

Two questionnaires were used: the Spanish versions of the specific CDDUX Coeliac disease questionnaire and the generic KIDSCREEN-52 questionnaire.

The Spanish version of the CDDUX questionnaire, which was previously validated by our group [12], contains 12 items distributed in 3 scales: "having CD" (3 items), which provides information on how the child feels when offered food that contains gluten or when thinking about food containing gluten; "communication" (3 items), which provides information about how the child feels when talking about $\mathrm{CD}$ to others or when explaining what the disease is; and "diet" (6 items), which provides information on how the child feels about having to follow a strict, lifelong diet or not being able to eat things that other people eat. Each item has 5 response options, aided by a picture diagram with faces expressing different corresponding emotional states. The CDDUX scores were recoded into a scale from 1 to 100 , with 1 being very bad and 100 very good. When using a 5-point Likert scale, a score of $1-20$ is considered very bad, $21-40$ is bad, $41-60$ is neutral, $61-80$ is good, and 81 to 100 is very good.

The Spanish version of the generic KIDSCREEN-52 questionnaire consists of 52 items covering 10 QOL domains $[9,10]$ : "social acceptance" (bullying), "moods and emotions", "physical well-being", "psychological wellbeing", "self-perception", "school environment", "parent relations and family life", "economic resources", "autonomy" and "social support and peers". Moreover, in the questionnaire's first question, the child or parent is asked about how they perceive their own, or their child's, state of health (excellent, very good, good, not $\mathrm{bad} / \mathrm{not}$ good, bad). The responses to the other 51 questions marked by patients and parents were transformed into a 5-point Likert-type scale in order to assess either the frequency (never, seldom, sometimes, often, always) of certain behaviours/feelings or the intensity of an attitude (not at all, slightly moderately, very, extremely). Children and adolescents were asked to select one response by recalling their situation over the period of the previous week by themselves. HRQOL was recorded on a scale from 1 to 100, with higher scores meaning a better HRQOL, like in the original version. Like with the CDDUX, HRQOL was considered "very bad" for scores 1-20, "bad" for scores 21-40, "neutral" for scores 41-60, "good" for scores 61-80 or "very good" for scores 81100. Both questionnaires have a version for children/adolescents aged 8 to 18 and another one for parents which had to be independently completed.

\section{Statistical analysis}

Kolmogorov-Smirnov (K-S) test was used to analyse the normality of variables. Results referring to the questionnaire scores in the different dimensions were provided as a mean (SD). Mean scores were compared by ANOVA according to the clinical and demographic variables included. Linear regression models were fitted to evaluate the association of the independent variables (demographic and clinical) with the dependent variables (HRQOL scores). Models were constructed including those variables which obtained a statistical significance in the univariate analysis $(p<0.05)$. CDDUX scores (quantitative variable) were compared with the subjective perception of health status assessed by the first question of KIDSCREEN-52. To evaluate the correlation between the dimensions of both questionnaires, the Pearson correlation coefficient $(r)$ and its statistical test were used.

All statistical tests were performed using the software package SPSS 15.0 for Windows (SPSS Inc., Chicago, IL, USA). Significance was set at $p<0.05$.

\section{Results}

The flowchart with the population included in the study is shown in Fig. 1. Demographics and clinical variables, are included in Table 1.

\section{HRQOL}

Mean total (SD) HRQOL CDDUX scores were 55. 5 (SD 12.7 ) and 53.89 (SD 12.19) in children and parents respectively, with no differences detected in paired comparisons between the two groups, except in the dimension "having coeliac disease", in which parents scored significantly higher than children $(p<0.001)$. (Table 1 of supplemental digital content). Whereas mean KIDSCREEN-52 scores ranged from 91.92 (SD 11.91) in the dimension "social acceptance" to 32.18 (SD 11.82) in "social support and peers" children and parents scored over 40 in 8 out of 10 KIDSCREEN-52 dimensions. Nevertheless, both scored their HRQOL as "bad" (scores between 20 and 40) in two dimensions: "autonomy" and "social support and peers." Children scored higher than parents in 5 dimensions while parents rated "social support and peers" higher. $(p<0.001)$. (Table 2 of supplemental digital content).

\section{QOL-related factors}

According to the fitted lineal regression models, nonclassical presentation at onset $(-3.71,95 \%$ CI -6.44 , $-0.98, p=0.008)$ and having economic or social difficulties with adhering to the diet $(-6.69,95 \% \mathrm{CI}$ $-10.59,-2.78, p=0.001)$ were detected as factors related to a decrease in HRQOL scores in the total mean CDDUX scores. Children having symptoms with 


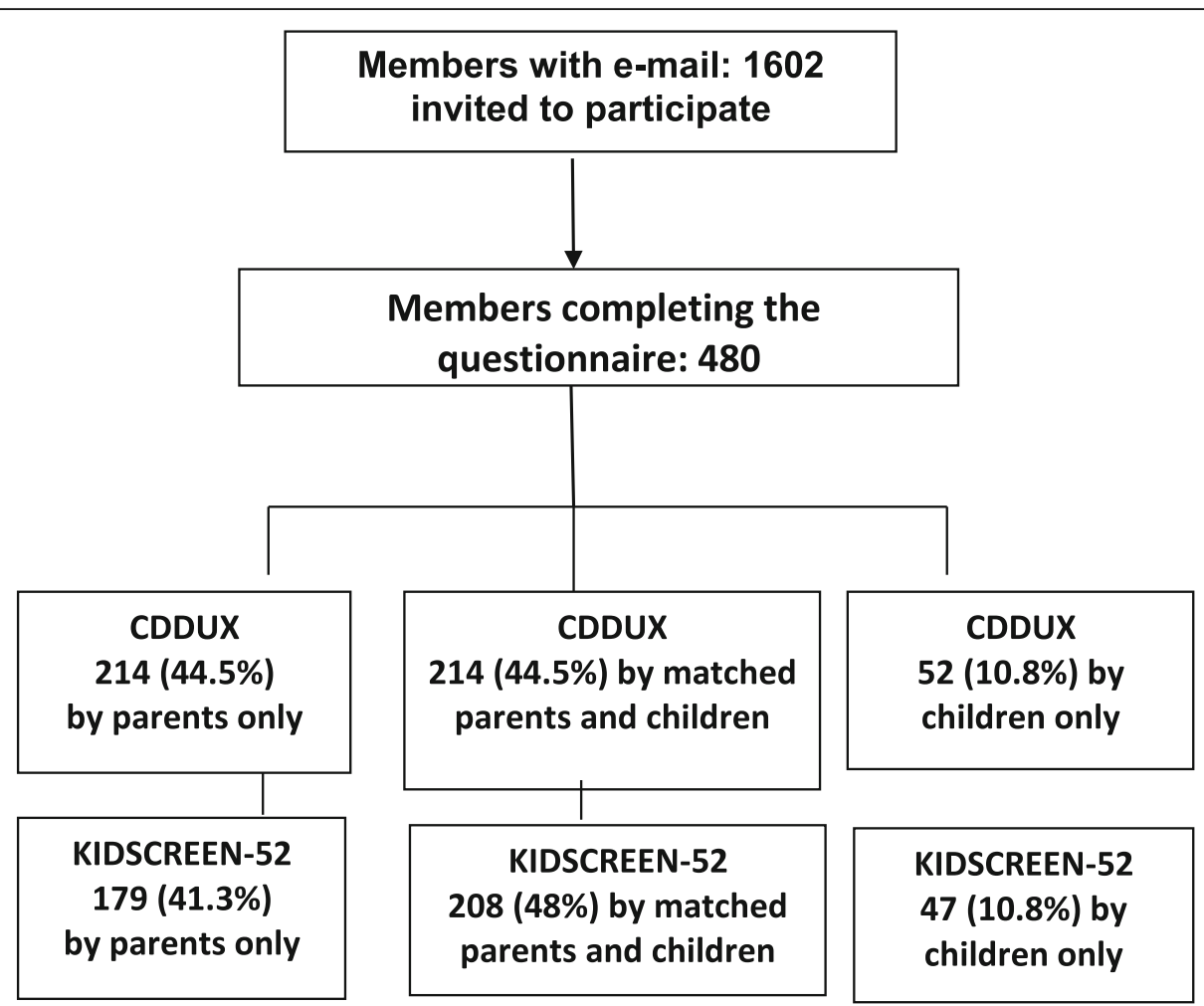

Fig. 1 Flowchart with the selection of the population included in the study

transgressions $(-2.70 ;$ IC $95 \%-5.16 ;-0.25 ; p=0.03)$ and those with less than 4 years since diagnosis (4.70; IC 95\%-7.91; - 1.48; $p=0.004$ ) scored lower in the "having CD" dimension. In addition, children younger than 2 years upon diagnosis scored better (3.8; IC 95\% $0.8 ; 6.8 ; p<0.001$ ) only on the communication scale. Patients with adherence to treatment scored higher in HRQOL in the total score (6.04, 95\% CI $-0.62,12.70, p=0.075)$ and in the communication and diet dimensions (Table 2).

When the KIDSCREEN-52 questionnaire was used (Table 3), some demographic factors were found to be related to a decrease in HRQOL: age older than twelve at the time the questionnaire was filled out (in mood and emotions, psychological and physical wellbeing and school dimensions); female gender (in psychological and physical wellbeing dimensions); and a time since diagnosis of less than 4 years (in psychological wellbeing and self-esteem dimensions). Furthermore, a decrease in HRQOL was observed in children who reported having economic and social difficulties in adhering to the diet and those having symptoms with transgressions.

Comparison of children's and parents' CDDUX scores and the subjective assessment of their health status

We compared mean scores of the children's $(n=255)$ and parents' $(n=387)$ CDDUX questionnaires regarding the subjective assessment of their health status (the first question of the KIDSCREEN-52 questionnaire) because the latter, in one single question, provides a general subjective idea about how respondents consider their own health status, so it is interesting to know if there is an agreement or not between the outcomes obtained with both questionnaires.

We observed that the higher the CDDUX scores observed in children and parents, the better the health status assessment $(p<0.01)$ in the total score and diet dimension. However, higher CDDUX scores observed in children and parents did not show a similar improvement in the health status assessment in the "having CD" dimension for children or parents nor in the communications dimension pertaining to the children (Table 4).

\section{Correlation between the questionnaires}

The correlation between the questionnaires was poor, being worse in children than parents. The maximum correlation obtained was 0.309 in parents and -0.254 in children. In children, the maximum correlations were inverse and were obtained between the "autonomy dimension" of KIDSCREEN-52 and all the dimensions of CDDUX. In parents, the best correlations between the questionnaires were positive and were obtained between the "mood and emotions" dimension of KIDSCREEN-52 
Table 1 Demographics and clinical variables

\begin{tabular}{|c|c|c|}
\hline & CDDUX & KIDSCREEN-52 \\
\hline CHILDREN (replies children/parents) & $480(266 / 214)$ & $434(255 / 179)$ \\
\hline Girls & $288(60 \%)$ & $269(62 \%)$ \\
\hline Age (years) & N (\%) & N (\%) \\
\hline $8-11$ & $188(39.2 \%)$ & $167(38.5 \%)$ \\
\hline $12-15$ & $225(46.9 \%)$ & $206(47.5 \%)$ \\
\hline $16-18$ & $67(14 \%)$ & $61(14.1 \%)$ \\
\hline Mean age (years) & $12.4(S D 2.8)$ & $12.4(S D 2.8)$ \\
\hline Median age at diagnosis (years) & $2(\mathrm{IQR} 2-5)$ & $2(\mathrm{IQR} 2-5)$ \\
\hline$<2$ & $60 \%$ & $61.3 \%$ \\
\hline $3-7$ & $22 \%$ & $20,3 \%$ \\
\hline$>7$ & $18 \%$ & $18.4 \%$ \\
\hline Mean time since diagnosis (years) & 8.4 (SD 4. 2) & 8.4 (SD 4. 2) \\
\hline$<4$ & $18.6 \%$ & $17.3 \%$ \\
\hline $5-8$ & $33.4 \%$ & $32.9 \%$ \\
\hline$>7$ & $48 \%$ & $49.8 \%$ \\
\hline Family history of CD & $20.6 \%$ & $20.7 \%$ \\
\hline \multicolumn{3}{|l|}{ Disease manifestation at onset } \\
\hline Classic form & $263(61.4 \%)$ & $239(61.8 \%)$ \\
\hline Non classic form & $160(37.4 \%)$ & $143(36.9 \%)$ \\
\hline Dermatitis herpetiformis & $2(0.5 \%)$ & $2(0.5 \%)$ \\
\hline During screening & $3(0.7 \%)$ & $3(0.7 \%)$ \\
\hline Associated conditions & $34(12.6 \%)$ & $34(12.6 \%)$ \\
\hline \multicolumn{3}{|l|}{ Medical follow-up } \\
\hline - Every two years & 12. $1 \%$ & $10.9 \%$ \\
\hline - Once a year & $71.5 \%$ & $71.5 \%$ \\
\hline - Every six months & $11.4 \%$ & $13.4 \%$ \\
\hline - Every three months & $1.6 \%$ & $1.7 \%$ \\
\hline - Occasionally & 1. $2 \%$ & $1.3 \%$ \\
\hline • Never & 2. $2 \%$ & $1.3 \%$ \\
\hline \multicolumn{3}{|l|}{ Adherence to the diet } \\
\hline • Always 96. 6\% & $414(96.7 \%)$ & $374(96.6 \%)$ \\
\hline - Most times 3. $1 \%$ & $13(3.03 \%)$ & 12(3. 1\%) \\
\hline - Sometimes $0.3 \%$ & $1(0.3 \%)$ & $1(0.3 \%)$ \\
\hline \multicolumn{3}{|l|}{ Difficulties with the diet } \\
\hline • No & $380(88.7 \%)$ & $346(89.4 \%)$ \\
\hline - Economic & $4(0.93 \%)$ & $4(1 \%)$ \\
\hline - Social & $12(2.8 \%)$ & $6(11 \%)$ \\
\hline - Eating out & $32(7.4 \%)$ & $26(6.7 \%)$ \\
\hline
\end{tabular}

$S D$ Standard deviation, IQR Interquartile range, $C D$ Coeliac Disease Classic form: signs and symptoms of malabsorption. Diarrhoea, steatorrhea weight loss or growth failure is required. Oslo 2012 Non-classic form: presents without signs and symptoms of malabsorption. (Oslo 2012)

Associated conditions: Diseases with increased prevalence of $C D$ and the "diet" dimension and total score of CDDUX (Table 5).

\section{Discussion}

In previous studies [12, 19], our group assessed the subjective HRQOL in coeliac children on a GFD and their parents, using two questionnaires, a specific one (CDDUX) and a generic one (KIDSCREEN-52). Coeliac children and their parents showed a neutral HRQOL experience using the CDDUX and a neutral to good HRQOL experience using the KIDSCREEN-52. Children scored higher than parents in most of the KIDSCREEN-52 dimensions, while they scored higher than parents in only one of the CDDUX dimensions. (supplemental digital content Tables 1 and 2). In general, we observed higher scores with the generic questionnaire when compared with the specific one, in line with findings from other investigators $[11,13,16,20]$. However, in our previous studies, both questionnaires showed some concerns regarding the HRQOL of our patients, which led us to take a deeper look and try to further elucidate factors related to having a worse perception of HRQOL [12, 19].

According to the multivariate analysis of our current study, we observed that the main factors related to having a worse HRQOL with both questionnaires were: having social and/or economic difficulties related to following the diet and having transgressionrelated symptoms. Moreover, in the CDDUX questionnaire, the non-complete adherence to diet, the non-classical form of $\mathrm{CD}$ at diagnosis and being older than 2 years of age upon diagnosis were found to be associated with having worse HRQOL while with the KIDSCREEN-52 questionnaire being female and being over 12 years of age when the survey was filled out were associated with a worse perception of HRQOL. In our previous studies [12, 19] with the CDDUX questionnaire, the univariate analysis showed the same factors related to having a worse HRQOL and these factors have now been confirmed by the multivariate analysis. Regarding the KIDSCREEN-52 questionnaire, non-complete dietary adherence was the only factor related to a worse HRQOL according to the univariate analysis that was not confirmed by the results in the current study. A negative perception of HRQOL in patients reporting non-adherence to the diet and with social or economic difficulties related to following the diet has been reported by other authors in children $[13,15,21,22]$ and adults [23-28] with CD. Feeling different in social and school settings, particularly among adolescents, has been assessed as an important factor influencing HRQOL in coeliac children [29]. Likewise, a negative association between HRQOL and having transgression-related symptoms has been reported by other authors [28]. 
Table $2 \mathrm{HRQOL}$ factors using CDDUX, based on scores given by the 428 parents who answered the questionnaire (linear regression models)

\begin{tabular}{|c|c|c|c|c|c|}
\hline & & Beta $^{a}$ & $p$-value & $95 \% \mathrm{Cl}$ & \\
\hline \multirow[t]{3}{*}{ TOTAL SCORE } & Non-Classical form vs others & -3.71 & 0.008 & -6.44 & -0.98 \\
\hline & Adherence to diet Yes/No & 6.04 & 0.075 & -0.62 & 12.70 \\
\hline & $\begin{array}{l}\text { Economic or social difficulties } \\
\text { vs. others }\end{array}$ & -6.69 & 0.001 & -10.60 & -2.78 \\
\hline \multirow[t]{6}{*}{ HAVING CD } & Time since diagnosis (years) & & & & \\
\hline & $<4$ vs. $>8$ & -4.69 & 0.004 & -7.91 & -1.48 \\
\hline & $4-8$ vs. $>8$ & -3.80 & 0.005 & -6.43 & -1.16 \\
\hline & Economic or social difficulties vs. others & -4.55 & 0.022 & $-8, .44$ & -0.67 \\
\hline & Transgression symptoms yes/ no & -2.70 & 0.031 & -5.16 & -0.25 \\
\hline & University studies: mother/ rest & 4.39 & $<0.001$ & 2.14 & 6.63 \\
\hline \multirow[t]{4}{*}{ COMMUNICATION } & Age upon diagnosis (years) $(<2$ vs. $=>2$ ) & 3.87 & 0.012 & 0.87 & 6.88 \\
\hline & Adherence to diet Yes/No & 10.96 & 0.009 & 2.71 & 19.21 \\
\hline & Economic or social difficulties vs. others & -5.81 & 0.021 & -10.73 & -0.90 \\
\hline & University studies: father vs others & -3.98 & 0.007 & -6.85 & -1.12 \\
\hline \multirow[t]{3}{*}{ DIET } & Non-Classical form vs. others & -4.50 & 0.011 & -7.99 & -1.02 \\
\hline & Adherence to diet (yes / no) & 8.36 & 0.054 & -0.13 & 16.87 \\
\hline & $\begin{array}{l}\text { Economic or social difficulties vs. } \\
\text { others }\end{array}$ & -8.83 & 0.001 & -13.82 & -3.84 \\
\hline
\end{tabular}

${ }^{a}$ Beta absolute mean effect; $C I$ Confidence interval, $C D$ Coeliac Disease, HRQOL Health-related Quality of life

Table $3 \mathrm{HRQOL}$ factors using KIDSCREEN-52, based on scores given by $n=387$ parents (linear regression models)

\begin{tabular}{|c|c|c|c|c|c|}
\hline \multirow[b]{2}{*}{ Social Acceptance } & \multirow[b]{2}{*}{ Social and economic difficulties vs. others } & \multirow{2}{*}{$\begin{array}{l}\text { Beta }^{a} \\
-6.386\end{array}$} & \multirow{2}{*}{$\begin{array}{l}p \text {-value } \\
0.002\end{array}$} & \multicolumn{2}{|c|}{ IC for $B$ at $95 \%$} \\
\hline & & & & -10.31 & -2.46 \\
\hline \multirow[t]{4}{*}{ Mood and emotions } & Age (12-15/8-11) & -2.82 & 0.024 & -5.28 & -0.37 \\
\hline & Age (16-18 / 8-11) & -4.88 & 0.010 & -8.56 & -1.19 \\
\hline & Social and economic difficulties vs others & -6.23 & 0.002 & -10.13 & -2.34 \\
\hline & Symptoms with transgressions & -3.19 & 0.009 & -5.57 & -0.80 \\
\hline \multirow[t]{6}{*}{ Psychological wellbeing } & Age $(12-15 / 8-11)$ & -2.02 & 0.033 & -3.87 & -0.17 \\
\hline & Age (16-18 / 8-11) & -6.27 & $<0.001$ & -9.02 & -3.51 \\
\hline & Gender (boy /girl) & 2.87 & 0.002 & 1.10 & 4.65 \\
\hline & Time since diagnosis $(<4 /=0>4)$ & -1.93 & 0.031 & -3.68 & -0.18 \\
\hline & Mother secondary studies / 1 & -3.43 & 0.006 & -5.68 & -1.00 \\
\hline & Mother University studies / 1 & -1.99 & 0.015 & -3.59 & -0.38 \\
\hline \multirow[t]{3}{*}{ Physical wellbeing } & Age (12-15/8-11) & -1.65 & 0.061 & -3.37 & 0.08 \\
\hline & Age (16-18/8-11) & -5.39 & $<0.001$ & -8.00 & -2.83 \\
\hline & Gender (boy/girl) & 2.55 & 0.003 & 0.90 & 4.20 \\
\hline \multirow[t]{3}{*}{ School environment } & Symptoms with transgressions yes/no & -1.36 & 0.004 & -0.44 & -2.29 \\
\hline & Age $(12-15 / 8-11)$ & -1.88 & $<0.001$ & -2.84 & -0.92 \\
\hline & Age $(16-18 / 8-11)$ & -3.55 & $<0.001$ & -4.97 & -2.13 \\
\hline \multirow[t]{5}{*}{ Self- perception } & Time since diagnosis $(<4 />8)$ & 2.26 & 0.068 & -0.17 & 4.68 \\
\hline & Time since diagnosis $(4-8 />8)$ & 1.90 & 0.091 & -0.30 & 4.10 \\
\hline & Age (12-15/8-11) & -2.07 & 0.050 & -4.13 & -0.00 \\
\hline & Age (16-18 / 8-11) & -4.58 & 0.002 & -7.53 & -1.63 \\
\hline & Social/economic difficulties vs. other & -5.03 & 0.001 & -7.90 & -2.15 \\
\hline
\end{tabular}


Table 4 Comparison between the first question in the KIDSCREEN-52, in relation to the subjective perception of health status, and the CDDUX scores (in the $n=255$ children and $N=387$ parents answered both questionnaires)

\begin{tabular}{|c|c|c|c|c|c|c|c|}
\hline & & $\mathrm{N}$ & $\begin{array}{l}\text { Children CDDUX } \\
\text { Mean SCORES (SD) }\end{array}$ & $\boldsymbol{p}$-value & & $\begin{array}{l}\text { Parents CDDUX } \\
\text { Mean SCORES } \\
\text { (SD) }\end{array}$ & $p$-value \\
\hline \multirow[t]{5}{*}{ Total } & Not bad-not good & 5 & $50.67(12.62)$ & 0.01 & 12 & 50.14 (15.69) & $<0.001$ \\
\hline & Good & 43 & $50.43(12.72)$ & & 93 & 50.14 (10.69) & \\
\hline & Very good & 122 & $55.23(12.22)$ & & 162 & $54.87(11.83)$ & \\
\hline & Excellent & 85 & $58.33(12.93)$ & & 120 & $58.88(13.37)$ & \\
\hline & Total & 255 & $55.37(12.78)$ & & 387 & $54.83(12.60)$ & \\
\hline \multirow[t]{5}{*}{ Having CD } & Not bad-not good & 5 & $52.00(5.58)$ & 0.63 & 12 & 46. $11(14.90)$ & 0.15 \\
\hline & Good & 43 & $45.12(12.07)$ & & 93 & $47.60(12.42)$ & \\
\hline & Very good & 122 & 46.99 (12.88) & & 162 & $49.51(12.58)$ & \\
\hline & Excellent & 85 & $45.80(14.28)$ & & 120 & $51.28(12.81)$ & \\
\hline & Total & 255 & $46.38(13.13)$ & & 387 & $49.49(12.73)$ & \\
\hline \multirow[t]{5}{*}{ Communication } & Not bad-not good & 5 & $69.33(19.78)$ & 0.27 & 12 & $61.67(10.68)$ & $<0.001$ \\
\hline & Good & 43 & $68.99(18.91)$ & & 93 & 64.95(13.72) & \\
\hline & Very good & 122 & $70.98(16.42)$ & & 162 & $69.51(15.64)$ & \\
\hline & Excellent & 85 & $74.67(16.83)$ & & 120 & $74.78(16.56)$ & \\
\hline & Total & 255 & 71.84 (17.09) & & 387 & $69.80(15.82)$ & \\
\hline \multirow[t]{5}{*}{ Diet } & Not bad-not good & 5 & $40.67(15.53)$ & $<0.001$ & 12 & $46.39(20.96)$ & $<0.001$ \\
\hline & Good & 43 & $43.80(16.91)$ & & 93 & $44.01(13.96)$ & \\
\hline & Very good & 122 & 51.48 (15.79) & & 162 & $50.23(14.60)$ & \\
\hline & Excellent & 85 & $56.43(18.33)$ & & 120 & $54.72(17.96)$ & \\
\hline & Total & 255 & $51.62(17.36)$ & & 387 & $50.01(16.23)$ & \\
\hline
\end{tabular}

SD Standard deviation, CD Coeliac Disease

The CDDUX questionnaire seems to be more sensitive for detecting differences in clinical variables. Therefore, children younger than 2 at the time of diagnosis scored better on their HRQOL, which is in line with reports from other authors $[17,30]$. The explanation behind this could be that the younger the child is upon diagnosis, the less accustomed to the taste of gluten-containing food he/she is and, therefore, the better the compliance with the gluten-free diet is. In our current study, the non-classical clinical presentation form for CD was associated with a worse perception of HRQOL according to the CDDUX results. However, no differences were found in clinical presentation with the KIDSCREEN-52 questionnaire, nor did other authors who used different questionnaires, such as Bystrom [17] and Choung [31], find them. In spite of this, the KIDSCREEN-52 questionnaire detected more differences in demographic variables, such as gender and age at the time of filling out the survey, as reflected in worse scores in children older than 12 years of age and in females. Nevertheless, neither our group using the Spanish CDDUX, nor other investigators that used the same questionnaire found differences in relation to those factors [11, 13, 17]. In both questionnaires, the group of children with less time since diagnosis experienced some aspects of their HRQOL as lower. The explanation could be related to a better acceptance of the disease and the diet as the time from diagnosis increases.

Mean CDDUX scores were compared with the subjective assessment of health status, as assessed with the first question of KIDSCREEN-52. Results showed that when patients had a better perception of their health status, the mean CDDUX scores were better as well, which agrees with the results obtained by other researchers [11].

Regarding our second objective, the correlation between the mean scores of the generic KIDSCREEN-52 and the specific CDDUX questionnaires was also assessed. We observed a poor correlation between the questionnaires, with worse results in children than in parents. These results are in line with those reported by Jordan et al. [16], which observed a poor to moderate correlation between the generic Pediatric Quality of Life Inventory (PedsQL) and the specific CDPQOL questionnaires in coeliac children, and those by Picó et al. [13], which found a moderate correlation between the CDDUX and the generic PedsQL questionnaires. The discrepancies between specific and generic questionnaires can be explained by the different types of information obtained, in addition to the different methodologies used in both of them. Specific CD 
Table 5 Correlation between CDDUX and KIDSCREEN scores ( $n=255$ children and $n=387$ parents)

\begin{tabular}{|c|c|c|c|c|c|c|c|c|c|}
\hline & & Children & Parents & Children & Parents & Children & Parents & Children & Parents \\
\hline \multirow[t]{2}{*}{ Social acceptance } & Pearson $r$ & 0.028 & 0.268 & 0.115 & 0.118 & 0.009 & 0.20 .243 & -0.006 & 0.252 \\
\hline & $\mathrm{p}$ & 0.656 & $<0.001$ & 0.068 & 0.020 & 0.891 & $<0.001$ & 0.920 & $<0.001$ \\
\hline \multirow[t]{2}{*}{ Moods and emotions } & Pearson $r$ & 0.208 & 0.307 & 0.057 & 0.168 & 0.138 & 0.211 & 0.217 & 0.309 \\
\hline & $\mathrm{p}$ & 0.001 & $<0.001$ & 0.363 & 0.001 & 0.028 & $<0.001$ & $<0.001$ & $<0.001$ \\
\hline \multirow[t]{2}{*}{ Psychological wellbeing } & Pearson $r$ & 0.136 & 0.148 & -0.058 & 0.054 & 0.096 & 0.202 & 0.175 & 0.110 \\
\hline & $\mathbf{p}$ & 0.030 & 0.004 & 0.357 & 0.292 & 0.124 & 0.000 & 0.005 & 0.031 \\
\hline \multirow[t]{2}{*}{ Physical wellbeing } & Pearson $r$ & 0.159 & 0.181 & -0.061 & 0.072 & 0.112 & 0.230 & 0.203 & 0.142 \\
\hline & $\mathbf{p}$ & 0.011 & 0.000 & 0.328 & 0.160 & 0.075 & 0.000 & 0.001 & 0.005 \\
\hline \multirow[t]{2}{*}{ Self- perception } & Pearson $r$ & 0.113 & 0.126 & -0.064 & 0.013 & -0.019 & 0.103 & 0.200 & 0.140 \\
\hline & $p$ & 0.071 & 0.013 & 0.309 & 0.800 & 0.758 & 0.042 & 0.001 & 0.006 \\
\hline \multirow[t]{2}{*}{ School environment } & Pearson $r$ & 0.012 & -0.039 & -0.020 & -0.080 & 0.028 & 0.031 & 0.011 & -0.044 \\
\hline & $p$ & 0.849 & 0.443 & 0.753 & 0.116 & 0.659 & 0.548 & 0.856 & 0.384 \\
\hline \multirow[t]{2}{*}{ Parent relations } & Pearson $r$ & -0.064 & -0.008 & 0.052 & 0.031 & -0.146 & -0.022 & -0.042 & -0.014 \\
\hline & $\mathrm{p}$ & 0.312 & 0.875 & 0.411 & 0.542 & 0.020 & 0.671 & 0.509 & 0.783 \\
\hline \multirow[t]{2}{*}{ Financial resources } & Pearson $r$ & -0.099 & -0.051 & -0.021 & -0.006 & -0.052 & 0.033 & -0.112 & -0.092 \\
\hline & $\mathrm{p}$ & 0.115 & 0.321 & 0.733 & 0.906 & 0.405 & 0.518 & 0.076 & 0.070 \\
\hline \multirow[t]{2}{*}{ Autonomy } & Pearson $r$ & -0.253 & -0.225 & -0.104 & -0.134 & -0.254 & -0.184 & -0.208 & -0.208 \\
\hline & $\mathrm{p}$ & 0.000 & 0.000 & 0.096 & 0.008 & 0.000 & 0.000 & 0.001 & 0.000 \\
\hline \multirow[t]{2}{*}{ Social support and peers } & Pearson $r$ & -0.203 & -0.226 & -0.136 & -0.175 & -0.198 & -0.190 & -0.151 & -0.189 \\
\hline & $\mathbf{p}$ & 0.001 & 0.000 & 0.029 & 0.001 & 0.002 & 0.000 & 0.016 & 0.000 \\
\hline
\end{tabular}

questionnaires focus on aspects of life that are influenced by having the disease and having to adhere to a restrictive diet throughout life, whereas generic questionnaires assess the different dimensions that condition the general HRQOL. The justification of that can be that the individual may have a good overall HRQOL but have problems related to their disease which are not detected by a generic questionnaire, hence the importance of using both questionnaires [26].

Our study has some limitations. Participants were all members of a coeliac association, which could introduce biases since these families would likely be highly motivated to deal with their child's problem. Similarly, as an inclusion criterion for this study was having an e-mail address, participants may not have been representative of low-income families. However, our study population is the best possible representation of the whole child $C D$ population in Madrid.

\section{Conclusions}

Although there is a poor correlation between the two questionnaires, both agreed that the main concerns of the respondents were related to the social and economic difficulties of following the diet. It would be interesting to use of both types of questionnaires in order to perform a more complete assessment of HRQOL in coeliac children.

\section{Supplementary information}

Supplementary information accompanies this paper at https://doi.org/10. 1186/s12955-020-01494-X

Additional file 1. Supplemental digital content. Table 1. Health-related quality of life (HRQOL) scores provided by 266 Spanish children with coeliac disease and parents (428) of children with coeliac disease using the specific CDDUX questionnaire. Supplemental digital content. Table 2. Health-related quality of life (HRQOL) scores provided by Spanish children with coeliac disease and parents of children with coeliac disease using the generic KIDSCREEN-52 questionnaire.

Abbreviations

CD: Coeliac disease; GFD: Gluten-free diet; MCA: Madrid Coeliac Association; Cl: Confidence interval; HRQOL: Health-related quality of life;

PedsQL: Pediatric Quality of Life Inventory (PedsQL); QOL: Quality of life

\section{Acknowledgements}

We are grateful to Dr. Maria Luisa Mearin for her expert advice when carrying out the work, to all the patients and their parents for their efforts in taking part in this study, and to the Madrid Coeliac Association for providing us with the patients' contact details.

\section{Authors' contributions}

Dr. Josefa Barrio is the main author of this work, and she is the responsible for writing the research protocol, conducting the research, extracting the data, interpreting the results, and writing the manuscript. No payments were given to any of the authors to produce the manuscript. Each author listed on the manuscript has seen and approved the submission of this version of the manuscript and takes full responsibility for the manuscript. Dr. Josefa Barrio designed the study, analyzed the data, drafted this manuscript, and agreed on the final version of this manuscript. Dr. Maria Luz Cilleruelo and Dr. Enriqueta Román participated in the design of this study, participated in the interpretation of data, revised the manuscript critically, and agreed on 
the final version of this manuscript. Cristina Fernández: provided advice and participated in study design, carried out statistical data analysis, is responsible for extracting the data and interpreting the results and agreed on the final version of this manuscript.

\section{Funding}

Study partially financed by "Fondo de Investigación Sanitaria (Spain)", Grant number PI12/01183. Fondos FEDER EC523. Website: www.isciii.es

\section{Availability of data and materials}

The dataset used for this research will be available from the corresponding author upon reasonable request.

\section{Ethics approval and consent to participate}

The study protocol was approved by the Clinical Research Ethics Committee of the Hospital Universitario de Fuenlabrada, Madrid, Spain. Informed consent was obtained from all parents or guardians and from all patients aged 12 years or older.

\section{Consent for publication}

Not applicable.

\section{Competing interests}

None declared.

\section{Author details}

'Department of Paediatrics, Hospital Universitario de Fuenlabrada, Madrid, Spain. ${ }^{2}$ Department of Paediatrics, Hospital Universitario Puerta Hierro, Madrid, Spain. ${ }^{3}$ Department of Epidemiology, Hospital Universitario Clínico de Madrid, Madrid, Spain.

Received: 20 January 2020 Accepted: 13 July 2020

Published online: 25 July 2020

\section{References}

1. Husby S, Koletzko S, Korponay-Szabó IR, et al. ESPGHAN working group on coeliac disease diagnosis; European Society for Paediatric Gastroenterology, hepatology, and nutrition guidelines for the diagnosis of coeliac disease. J Pediatr Gastroenterol Nutr. 2012;54:136-160.

2. Altobelli $E$, Paduano $R$, Gentile $T$, et al. Health related quality of life in children and adolescents with celiac disease: survey of a population from Central Italy. Health Qual Life Outcomes. 2013;11:204.

3. Rashid M, Cranney A, Zakadas M, et al. Celiac disease: evaluation of the diagnosis and dietary compliance in Canadian children. Pediatrics. 2005; 116(6):e754-9.

4. Sevinç E, Çetin FH, Coşkun BD. Psychopathology, quality of life, and related factors in children with celiac disease. J Pediatr. 2017:93:267-73.

5. Meyer S, Rosenblum S. Children with celiac disease: health-related quality of life and leisure participation. Am J Occup Ther. 2016;70:7006220010p1-8. https://doi.org/10.5014/ajot.2016.020594

6. Vriezinga SL, Farih N, van der Meulen-de Jong AE, et al. Comparison of Patients' and Doctors' reports on health-related quality of life in celiac disease. J Pediatr Gastroenterol Nutr. 2017;64:737-41.

7. White LE, Bannerman E, Gillett PM. Coeliac disease and the gluten-free diet: a review of the burdens; factors associated with adherence and impact on health-related quality of life, with specific focus on adolescence. J Hum Nutr Diet. 2016;29:593-606.

8. Patrick DL, Deyo RA. Generic and disease-specific measures in assessing health status and quality of life. Med Care. 1989;27(3 Suppl):S217-32. https://doi.org/10.1097/00005650-198903001-00018.

9. Ravens-Sieberer U, Herdman M, Devine J, et al. The European KIDSCREEN approach to measure quality of life and well-being in children: development, current application, and future advances. Qual Life Res. 2014; 23:791-803.

10. Tebe C, Berra S, Herdman M, et al. Reliability and validity of the Spanish version of the KIDSCREEN-52 for child and adolescent population. Med Clin (Barc). 2008;130:650-4. https://doi.org/10.1157/13120999.

11. Van Doorn RK, Winkler LM, Zwinderman KH, et al. CDDUX: a disease-specific health-related quality-of-life questionnaire for children with celiac disease. J Pediatr Gastroenterol Nutr. 2008;47:147-52.
12. Barrio J, Cilleruelo ML, Roman E, et al. Health-related quality of life in Spanish children with coeliac disease. J Pediatr Gastroenterol Nutr. 2016;62: 603-8.

13. Picó M, Spirito MF, Roizen M. Quality of life in children and adolescents with celiac disease: Argentinian version of the specific questionnaire CDDUX. Acta Gastroenterol Latinoam. 2012;42:12-9 PMID: 22616492.

14. Lins MTC, Tassitano RM, Brandt KG, et al. Translation, cultural adaptation, and validation of the celiac disease DUX (CDDUX). J Pediatr. 2015;91:448-54.

15. Taghdir M, Honar N, Mazloomi SM, et al. Dietary compliance in Iranian children and adolescents with celiac disease. J Multidiscip Healthc. 2016;9: 365-70.

16. Jordan NE, Li Y, Magrini D, et al. Development and validation of a celiac disease quality of life instrument for north American children. J Pediatr Gastroenterol Nutr. 2013;57:477-86.

17. Byström IM, Hollén $E$, Fälth-Magnusson $\mathrm{K}$, et al. Health-related quality of life in children and adolescents with celiac disease: from the perspectives of children and parents. Gastroenterol Res Pract. 2012;2012:986475. https://doi. org/10.1155/2012/986475.

18. Myléus A, Petersen S, Carlsson A, et al. Health-related quality of life is not impaired in children with undetected as well as diagnosed celiac disease: a large population based cross-sectional study. BMC Public Health. 2014;14: 425.

19. Barrio J, Cilleruelo ML, Roman E, et al. Health-related quality of life in Spanish coeliac children using the generic KIDSCREEN-52 questionnaire. Eur J Pediatr. 2018;177:1515-22.

20. Van Koppen EJ, Schweizer JJ, Csizmadia CG, et al. Long-term health and quality-of-life consequences of mass screening for childhood celiac disease: a 10-year follow-up study. Pediatrics. 2009;123:e582-8.

21. Wagner G, Berger G, Sinnreich U. Quality of life in adolescents with treated coeliac disease: influence of compliance and age at diagnosis. J Pediatr Gastroenterol Nutr. 2008;47:555-61.

22. Simsek S, Baysoy G, Gencoglan S, et al. Uluca U. effects of gluten-free diet on quality of life and depression in children with celiac disease. J Pediatr Gastroenterol Nutr. 2015;61:303-6.

23. Tontini GE, Rondonotti E, Saladino V, et al. Impact of gluten withdrawal on health-related quality of life in celiac subjects: an observational case-control study. Digestion. 2010;82:221-8.

24. Usai P, Manca R, Cuomo R, et al. Effect of gluten-free diet and co-morbidity of irritable bowel syndrome-type symptoms on health-related quality of life in adult coeliac patients. Dig Dis Liver. 2007;39:824-8.

25. Haüser W, Musial F, Caspary WF, et al. Predictors of irritable bowel-type symptoms and healthcare seeking behaviour among adults with coeliac disease. Psycosom Med. 2007;69:370-6.

26. Burger JPW, de Brouwer B, Int Hout J, et al. Systematic review with metaanalysis: dietary adherence influences normalization of health-related quality of life in coeliac disease. Clin Nutr. 2017:36:399-406.

27. C D, Berry N, Vaiphei K, Dhaka N, Sinha SK, Kochhar R. Quality of life in celiac disease and the effect of gluten-free diet. JGH Open. 2018:2:124-8.

28. Casellas F, Rodrigo L, Lucendo AJ, et al. Benefit on health-related quality of life of adherence to gluten-free diet in adult patients with celiac disease. Rev Esp Enferm Dig. 2015;107:196-201 PMID: 25824917.

29. Mager DR, Marcon M, Brill H, et al. Adherence to the gluten-free diet and health-related quality of life in an ethnically diverse pediatric population with celiac disease. J Pediatr Gastroenterol Nutr. 2018;66:941-8.

30. Högberg L, Grodzinsky E, Stenhammar L. Better dietary compliance in patients with coeliac disease diagnosed in early childhood. Scand J Gastroenterol. 2003:38:751-4.

31. Choung RS, Lamba A, Marietta EV, et al. Effect of a gluten-free diet on quality of life in patients with nonclassical versus classical presentations of celiac disease. J Clin Gastroenterol. 2019 Oct 31. https://doi.org/10.1097/ MCG.0000000000001277 [Epub ahead of print]. Accessed 25 Nov 2019.

\section{Publisher's Note}

Springer Nature remains neutral with regard to jurisdictional claims in published maps and institutional affiliations. 